\title{
Article
}

Mycosphere

\section{The zombie ants parasitized by the fungi Ophiocordyceps camponoti- atricipis (Hypocreales: Ophiocordycipitaceae): new occurrence and natural history}

\author{
Sobczak JF ${ }^{1}$, Costa LFA ${ }^{1}$, Carvalho JLVR ${ }^{1}$, Salgado-Neto G $^{2}$, Moura-Sobczak \\ JCMS $^{1}$ and Messas YF $^{3}$
}

\begin{abstract}
${ }^{1}$ Instituto de Ciências Exatas e da Natureza, Universidade da Integração Internacional da Lusofonia Afro-Brasileira, Rod. CE 040, Acarape, CE, Brasil. jobczak@gmail.com, leticiafranco.a@hotmail.com, lucasvitorio@aluno.unilab.edu.br,sobczak@unilab.edu.br

${ }^{2}$ Departamento de Defesa Fitossanitária, Universidade Federal de Santa Maria, 97105-900, Santa Maria, RS, Brasil. gsalgado@bol.com.br

${ }^{3}$ Departamento de Biologia Animal, Instituto de Biologia, Universidade Estadual de Campinas, 13083-862, Campinas, São Paulo, Brasil. yurimessas@gmail.com
\end{abstract}

Sobczak JF, Costa LFA, Carvalho JLVR, Salgado-Neto G, Moura-Sobczak JCMS, Messas YF 2017 - The zombie ants parasitized by the fungi Ophiocordyceps camponoti-atricipis (Hypocreales: Ophiocordycipitaceae): new occurrence and natural history. Mycosphere 8 (9), 1261-1266, Doi 10.5943/mycosphere/8/9/1

\begin{abstract}
The entomopathogenic fungus Ophiocordyceps camponoti-atricipis parasitizes the ant species Camponotus (Myrmothrix) atriceps in the Brazilian Central Amazon, and may induce behavioral changes in its hosts. In this study, we extended the distribution range of this interaction for the Atlantic Forest biome. In addition, we investigated the occurrence of parasitized ants fixed upon specific host plants, plant structures and heights above the soil. We found higher frequencies of ants on the introduced plant of commercial value Coffea arabica. The ants adhered to the plants using their mandibles, normally on the abaxial surface and central veins of leaves. The fungus killed its hosts preferentially at a height of $1 \mathrm{~m}$ to $2.5 \mathrm{~m}$ above the soil, differing from that observed in other studies.
\end{abstract}

Key words - behavioral manipulation - Camponotus atriceps - entomopathogenic fungi Neotropical -rainforest.

\section{Introduction}

Host manipulation induced by parasites are broadly distributed in the nature and it has been a topic of several studies over the past decades (Thomas et al. 2010). Specific associations between arthropods and parasitic fungi are relatively well known for a variety of groups, including Araneae, Coleoptera, Hymenoptera and Hemiptera (Araújo \& Hughes 2016). Eberhard et al. (2014), for example, showed that Edessa rufomarginata (De Geer, 1773) (Hemiptera, Pentotomidae), when infected by the fungus Purpureocillium cf. lilacinum (Ascomycota: Ophiocordycipitaceae), exhibits the unusual behavior of moving from the leaves onto the stems of their host plant and firmly grasp the stems. 
Infections of ants by entomopathogenic fungi have been reported in several regions of the world, such as Asia, Australasia, Africa and the Americas (Pontoppidan et al. 2009). These interactions often occur as epizootics, contaminating a large number of ant specimens in small forest regions (Andersen et al. 2009, Pontoppidan et al. 2009). The possibility of acting directly and indirectly on the abundance of its hosts and, therefore, presenting an important function on communities' energy flow, makes studies on ant-fungi interactions highly recommended (Hudson et al. 2006).

Among these associations, it is known that Ophiocordyceps species (Hypocreales: Ophiocordycipitaceae) can parasitize several ant species from basal groups (e.g. Ponerines) to modern genera (e.g. Camponotus) (Evans \& Samson 1982, Sanjuan et al. 2011, Evans et al. 2011). In a study conducted in Thailand, Hughes et al. (2011) showed that Ophiocordyceps unilateralis sensu lato (Tul. \& C. Tul.) Petch, 1931 manipulates the behavior of the ant Camponotus leonardi Emery, 1889. The authors observed parasite-infected ants fixed through its mandibles to the abaxial veins of leaves, a behavior which is not apparent in healthy ants of this species. According to Andersen et al. (2009), this behavior is adaptable to the fungus, ensuring a stable microclimatic niche for its development after the host's death and facilitating aerial dispersion of the spores.

Araújo et al. (2015) described three species of Ophiocordyceps that infect Camponotus ants, among them $O$. camponoti-atricipis, the target species of this study. Species belonging to $O$. unilateralis complex triggers a series of synchronized events within the host to induce it to leave the colony towards the understory, where it dies in an elevated and strategic position, characteristically attaching itself to abaxial vein or edges of leaves. Once there, the spore-producing structure (stroma) emerges from the anterior intersegmental region to the pronotum, from which the ascospores actively release their spores after a few weeks of maturation (Andersen et al. 2009, Araújo et al. 2015). After releasing, the spores are deposited on the forest floor, where they will infect other ants that eventually pass through the site. Invasion of the host body occurs through the cuticle and the corpses are predominantly found in areas where the density of ants previously manipulated and killed by the fungus is already quite high, called graveyards (Pontoppidan et al. 2009).

In Brazil, natural epizootics caused by fungi $O$. unilateralis were recorded in adult individuals of ants Camponotus sp. in the Amazon Forest (Andrade 1980, Evans \& Samson 1982, 1984). In the southeast, Evans et al. (2011) described four new species with conspicuous different microscopic characteristics, but with morphology similar to that of $O$. unilateralis. The authors found that $O$. unilateralis is actually a complex of species, which has been confirmed in subsequent studies (Kepler et al. 2011, Luangsa-Ard et al. 2011, Kobmoo et al. 2012, Araújo et al. 2015). After this recent discovery, little research was done on the ecology and distribution of these fungi species.

In this study, we aimed to extend the occurrence area of the association between the fungus

$O$. camponoti-atricipis and its host ant $C$. atriceps. In addition, we investigated (1) the occurrence of host plant specificity by parasitized ants, (2) which plant structures are used by ants as attachment substrate, and (3) whether the death of parasitized ants occurs frequently in specific heights above the ground.

\section{Materials \& Methods}

\section{Study area}

The study was conducted in a Montane semi-deciduous tropical forest located in the municipally of Mulungu, Ceará State, Brazil (4'18'40' S, 38 58' 05' ' W, altitude of $840 \mathrm{~m}$ ). This locality is quite peculiar, because it represents one of the few remnants of Atlantic Forest within a semi-arid region (Oliveira \& Araújo 2007). This unusual feature results in a warm (mean annual temperature $20.8^{\circ} \mathrm{C}$ ) and humid (average precipitation $1221 \mathrm{~mm}$ ) climate, with a high heterogeneous vegetation. The area contains both native and introduced plant species. The coffee 
Coffea arabica, for example, is cultivated in a sustainable manner in shaded areas (Saes et al. 2003).

\section{Data acquisition}

We carried out two exploratory collection expeditions on November 2014 and August 2015. At this stage, we made visual search for ants infected by entomopathogenic fungi. We collected and individualized the ants in plastic containers, which were transported to the laboratory. We performed the identification and characterization of the fungus and its hosts through the analysis of morphological characteristics according to Araújo et al. (2015). We deposited specimens of both the fungus Ophiocordyceps camponoti-atricipis and the ant Camponotus atriceps in the entomological collection of the Museum of Zoology, University of São Paulo - MZUSP (Brandão, curator).

Additionally, we conducted a third expedition on November 2016 to obtain data on the ecology of this interaction. We performed a visual search for ants parasitized by $O$. camponotiatricipis along transects in trails of the study site. For each ant found, we recorded (1) the host plant species, (2) the plant structure where the ant died (3) the part of the structure used by the ant for attachment and (4) the height above the soil.

\section{Data analysis}

To verify if parasitized ants occur randomly or more frequently in (1) certain plant species, (2) specific plant structures and (3) heights above the ground, we compared expected with observed frequencies for each attribute. To analyze the specificity of ants for host plant species, we considered the available species in the study area to determine the expected frequencies, and we compared with the observed frequencies of plant species effectively used by the ants as a substrate. To determine which plant structures and heights above the ground were frequently used by parasitized ants, we compared the frequencies of structures/heights in which we found ants (observed frequencies) with frequencies expected at random. For all the analysis, we used $\mathrm{G}$ tests with significance being set at 0.05 (Sokal \& Rohlf 1994, Zar 1998) through the software BioEstat 5.3 .

\section{Results}

\section{Fungi characteristics}

All parasitized ants presented an abundant and visible external mycelium covering its thorax and mouthparts (Fig. 1a). The fruiting bodies of the fungi are initially white, turning light-brown over time. Stroma single produced from dorsal pronotum, averaging 8.6-16.9 mm, cylindrical, velvety and ginger brown at the base, becoming cram-pinkish towards apex. Fertile region of lateral cushions chocolate brown, darkening with age, variable in size. Perithecia immersed in the stroma, partially erumpent, flask-shaped, averaging 2-2.3 $\mathrm{mm}$. Region near the stroma basis with short, exposed neck or ostiole, averaging $0.8-1.4 \mathrm{~mm}$ above the ant's dorsal pronotum.

\section{Host plants}

In total, we found 106 parasitized ants, most of them $(77.36 \%, n=82)$ upon the introduced plant Coffea arabica (Rubiaceae). We also found ants on leaves of ginger Citrus reticulata (Citreae; 10.38\%, n=11), tipi Petiveria alliacea (Phytolaccaceae, 1.89\%, $\mathrm{n}=2$ ), and on some unidentified species of native plants $(9.43 \%, \mathrm{n}=10)$. Only one individual $(0.94 \%)$ was adhered to a climbing vine. In a few regions of the study area, we observed a high frequency of contamination and parasitism, exceeding the number of 20 parasitized individuals per square meter.

\section{Plant structures}

The parasitized ants died more frequently on leaves $(92.45 \%, \mathrm{n}=98)$. Other plant structures used by ants as a fixation site were stems $(n=3)$, branches $(n=2)$, vines $(n=2)$ and tendrils $(n=1)$. 

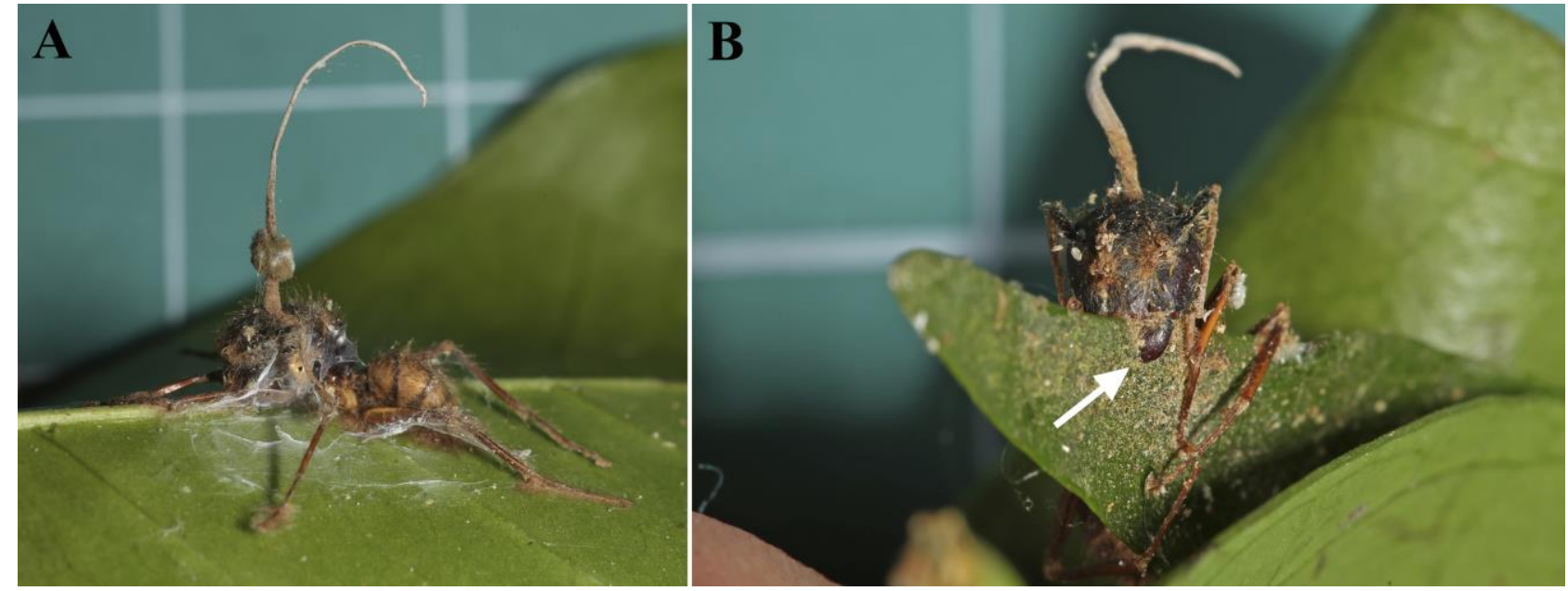

Fig. 1 - a Camponotus atriceps parasitized by the fungus Ophiocordyceps camponoti-atricipis. b Infectedant attached to a leave using its mandible (white arrow).



Fig. 2 - Expected and observed frequencies of heights above the soil containing ants Camponotus atriceps parasitized by the fungus Ophiocordyceps camponoti-atricipis.

All individuals found on the leaves were adhered through their mandibles to the leaf margins or to the central vein of the abaxial surface (Fig. 1b). When we compared the observed frequencies of structures used by the ants as substrate with the frequencies expected at random, we found higher frequency of individuals adhered to the central veins than to the leaf margins $(\mathrm{G}=4.4729$, $p=0.0494$ ).

\section{Height above the soil}

We observed high variation in heights in which the parasitized ants died, ranging from 15 $\mathrm{cm}$ to $290 \mathrm{~cm}$ above the soil, with average height of $171 \pm 57 \mathrm{~cm}$ (mean \pm standard deviation). However, despite this broad extend, the frequencies of ants at heights between 100 and $250 \mathrm{~cm}$ were significantly higher than that expected at random (Fig. 2; G=28.3959, p<0.0001).

\section{Discussion}


Although it occurs in both native and introduced plant species, most of parasitized ants were found upon the introduced plant $C$. arabica. Differently, Araújo et al. (2015) found parasitized ants principally on leaves and thorns of Arecaceae species. In another study, Hughes et al. (2011) found dead ants attached to a wide range of plant species, including monocotyledons and eudicots. We recommend future studies that investigate the association between parasitized $C$. atriceps and $C$. arabica, as well as whether there are positive and/or negative effects of the fungus presence on this plant, which presents important economic value in the studied region.

The observed frequency of parasitized $C$. atriceps at heights above the soil ranging from 100 to $250 \mathrm{~cm}$ contrasts with that observed by Hughes et al. (2011) in C. leonardi, most frequently at $25 \mathrm{~cm}$ in height. The authors discussed that low heights provide more favorable conditions for the fungus development. To our study, we suggest that the preference of higher heights occurs due to the type and structures provided by the coffee plants. However, as Hughes et al. (2011) deal with other fungus-ant species and distinct regions, the differences between $C$. atriceps and $C$. leonardi may be related to natural history traits and specific needs of the species involved in each interaction. Moreover, specific evolutionary adaptations to abiotic factors, such as temperature and precipitation, may also be considered.

In this study, we recorded for the first time the behavioral manipulation of the fungus $O$. camponoti-atricipis parasitizing the ants $C$. atriceps for the Atlantic Forest biome and also for the Brazilian northeast. This finding increases the information about the geographic distribution of the fungus and the interaction with its host ants, as well as the entire O. unilateralis complex. The natural occurrence in Camponotini ants suggests that this fungus may play an important role in ant control, and should encourage more extensive studies on the possibility of manipulating this fungus to be used in biological control programs.

\section{Acknowledgements}

We thank João Paulo Machado de Araújo for the identification of the fungi. We also thank Sr. Francisco Huerson Andrade by the access of the study area. This study was finantially supported by Programa Institucional de Iniciação Cientifica - PIBIC-UNILAB (grants to João Lucas Vitório Ribeiro Carvalho and Letícia Franco de Almeida Costa), Conselho Nacional de Ciência e Tecnologia - CNPq - Universal Edital, project 446473/2014-6, and Fundação Cearense de Apoio ao Desenvolvimento.

\section{References}

Andersen SB, Gerritsma S, Yusah KM, Mayntz D et al. 2009 - The life of dead ant: the expression of an adaptive extended phenotype. American Naturalist 174, 424-33.

Andrade FS. 1980 - Epizootia natural causada por Cordyceps unilateralis (Hypocreales, Euascomycetes) em adultos de Camponotus sp. (Hymenoptera, Formicidae) na região de Manaus, Amazonas, Brasil. Acta Amazonica 10, 671-677.

Araújo JPM, Hughes DP. 2016 - Diversity of Entomopathogenic Fungi: Which groups conquered the insect body? 1-39. Genetics and Molecular Biology of Entomopathogenic Fungi, eds. Lovett B, Leger RS. Academic Press, New York.

Araújo JPM, Evans HC, Geiser DM, Mackay WP, Hughes DP. 2015 - Unravelling the diversity behind the Ophiocordyceps unilateralis (Ophiocordycipitaceae) complex: Three new species of zombie-ant fungi from the Brazilian Amazon. Phytotaxa 220, 224-238.

De-Geer C. 1773 - Mémoires pour servir à l'histoire des insectes. Grefing \& Hesselberg, Stockholm.

Eberhard WG, Pacheco-Esquivel J, Carrasco-Rueda F, Christopher Y et al. 2014 - Zombie bugs? The fungus Purpureocillium sp. may manipulate the behavior of its host bug Edessa rufomarginata. Mycologia 106, 1065-1072.

Emery C. 1889 - Formiche di Birmania e del Tenasserim raccolte da Leonardo Fea (1885-87). Annali del Museo Civico di Storia Naturale di Genova, series 2, 27(7), 485-520. 
Evans HC, Samson RA. 1982 - Cordyceps species and their anamorphs pathogenic on ants (Formicidae) in tropical forest ecosystems. I. The Cephalotes (Myrmicinae) complex. Transactions of the British Mycological Society 79, 431-453.

Evans HC, Samson RA. 1984 - Cordyceps species and their anamorphs pathogenic of ants (Formicidae) in tropical forest ecosystems II. The Camponotus (Formicinae) complex. Transactions of the British Mycological Society 82, 127-150.

Evans HC, Elliot SL, Hughes DP. 2011 - Hidden diversity behind the zombie-Ant fungus Ophiocordyceps unilateralis: four new species described from carpenter ants in Minas Gerais, Brazil. PLoS ONE 6, e17024.

Hudson PJ, Dobson AP, Lafferty KD. 2006 - Is a healthy ecosystem one that is rich in parasites? Trends in Ecology and Evolution 21, 381-385.

Hughes DP, Wappler T, Labandeira CC. 2011 - Ancient death-grip leaf scars reveal ant-fungal parasitism. Biology Letters 7, 67-70.

Kepler RM, Kaitsu Y, Tanaka E, Shimano S, Spatafora JW. 2011 - Ophiocordyceps pulvinata sp. nov., a pathogen of ants with a reduced stroma. Mycoscience 52, 39-47.

Kobmoo N, Mongkolsamrit S, Tasanathai K, Thanakitpipattana D, Luangsa-Ard JJ. 2012 Molecular phylogenies reveal host-specific divergence of Ophiocordyceps unilateralis sensu lato following its host ants. Molecular Ecology 21, 3022-3031.

Luangsa-Ard JJ, Ridkaew R, Tasanathai K, Thanakitpipattana D, Hywel-Jones N. 2011 Ophiocordyceps halabalaensis: a new species of Ophiocordyceps pathogenic to Camponotus gigas in Hala Bala Wildlife Sanctuary, Southern Thailand. Fungal Biology 115, 608-614.

Oliveira TS, Araújo FS. 2007 - Diversidade e conservação da biota na Serra de Baturité, Ceará. Editora da Universidade Federal do Ceará, Fortaleza.

Petch T. 1931 - Notes on entomogenous fungi. Transactions of the British Mycological Society16, $55-75$.

Pontoppidan MB, Himaman W, Hywel-Jones NL, Boomsma JJ, Hughes DP. 2009 - Graveyards on the move: The spatio-temporal distribution of dead Ophiocordyceps-infected ants. PLoS ONE 4(3), e4835.

Saes MSM, Souza MCM, Otani MN. 2003 - Strategic alliances and sustainable coffee production: the shaded system of Baturite, state of Ceara, Brazil. International Food and Agribusiness Management Review 6, 19-29.

Sanjuán T, Henao LG, Amat G. 2001 - Distribución espacial de Cordyceps spp, (Ascomycotina: Clavicipitaceae) y su impacto sobre las hormigas en selvas del piedemonte amazónico de Colombia, Revista de Biología Tropical 49, 945-955.

Sokal RR, Rohlf FJ. 1994 - Biometry: the principles and practice of statistics in biological research. W. H. Freeman and Company, New York.

Thomas F, Poulin R, Brodeus J. 2010 - Host manipulation by parasites: a multidimensional phenomenon. Oikos 119, 1217-1223.

Zar JH. 1998 - Biostatistical analysis. Upper Saddle River: Prentice Hall, New Jersey. 